\title{
Metode Modifikasi Histogram Untuk Peningkatan Kontras dan Kecerahan Citra
}

\author{
Phie Chyan ${ }^{1}$ \\ ${ }^{1}$ Universitas Atma Jaya Makassar \\ ${ }^{1}$ phiechyan@gmail.com \\ Jl.Tanjung Alang no 23 Makassar, Indonesia
}

\begin{abstract}
Histogram Equalization is the method most often used to increase contrast in digital images. As a result, images that are processed using the HE method have negative effects such as the appearance that looks blurry and contours that change due to changes in image brightness. To overcome this problem, an HE model is needed that can maintain image brightness. Generally, the method partitioned the histogram from the original image into the sub histogram and then independently equalized the sub histogram. This study produced a simple histogram modification framework for contrast enhancement in immovable images to enhance image contrast without losing detail of the image features. The method presented consists of 2 stages. First, the histogram of the original image is modified to the general histogram. In the second stage, the modified histogram in the original image is separated into two sub-histograms based on the mean of the original image and then independently equalizes to maintain the brightness of the image. By using enhancement parameters, the level of contrast enhancement can be adjusted based on the contrast of the input image. The experimental results show that this method maintains better image brightness and produces images that look more natural than the results of other conventional methods. The method used has been tested using various types of images and provides better visual quality compared to other methods.
\end{abstract}

Abstrak- Histogram Equalization adalah merupakan metode yang paling sering digunakan untuk meningkatkan kontras pada citra digital. Sebagai hasilnya citra yang diproses menggunakan metode HE memiliki efek negatif seperti tampilan yang kelihatan buram dan kontur yang berubah akibat perubahan pada kecerahan gambar. Untuk mengatasi masalah tersebut diperlukan model HE yang dapat memelihara tingkat kecerahan citra. Umumnya, metode tersebut mempartisi histogram dari citra asli ke dalam sub histogram dan kemudian secara independen melakukan ekualisasi terhadap sub histogram tersebut. Penelitian ini menghasilkan suatu kerangka modifikasi histogram sederhana untuk kontras enhancement pada citra tak bergerak untuk meningkatkan kontras citra tanpa kehilangan detail dari fitur citra. Metode yang disajikan terdiri dari 2 tahap. Pertama, histogram dari citra asli di modifikasi terhadap histogram umum. Pada tahap kedua, histrogram yang dimodifikasi pada citra asli dipisahkan kedalam dua sub-histogram berdasarkan rataan dari citra asli dan kemudian melakukan ekualisasi secara independen untuk menjaga kecerahan citra. Dengan menggunakan parameter enhancement, tingkat dari enhancement kontras dapat disesuaikan berdasarkan kontras citra input. Hasil eksperimen menunjukkan bahwa metode ini mempertahankan kecerahan citra lebih baik dan menghasilkan citra yang terlihat lebih alami dibandingkan dengan hasil dari metode konvensional yang lain. Metode yang digunakan telah diuji menggunakan berbagai jenis citra dan memberi kualitas visual yang lebih baik dibandingkan dengan metode lain.

Keywords - Histogram Equalization, Modifikasi Histogram, Kecerahan Citra, Partisi Histogram.

\section{Pendahuluan}

Image enhancement merupakan salah satu permasalahan yang penting dalam bidang pengolahan citra digital. Tujuan utama dari image enhancement adalah untuk memperkuat detail tersembunyi dari suatu citra atau untuk meningkatkan kadar kontras pada citra berkontras rendah [1]. Image enhancement menghasilkan citra output yang secara subjektif terlihat lebih baik dari citra asli dengan jalan mengubah intensitas piksel dari citra input [2].

Saat ini terdapat banyak metode dalam melakukan image enhancement. Salah satu yang paling banyak digunakan adalah Histogram Equalization (HE). HE banyak digunakan dalam contrast enhancement karena metode ini mudah diimplementasikan dan efektif. HE melebarkan dan meratakan dynamic range dari histogram resultan citra sehingga memperkaya kontras dari citra dan memberi peningkatan kontras secara keseluruhan [3]. HE jarang diimplementasikan pada aplikasi konsumer seperti video pengawas, kamera digital dan televisi karena $\mathrm{HE}$ cenderung menghasilkan artefak yang mengganggu dan citra yang kurang alami termasuk efek peningkatan saturasi yang tidak diinginkan. Penyebab dari hal ini adalah karena HE umumnya mengubah kecerahan dari gambar secara signifikan dan membuat citra output menjadi tersaturasi dengan nilai intensitas sangat terang atau gelap. Oleh kerena itu kemampuan mempertahankan kecerahan citra merupakan karakteristik penting yang dibutuhkan untuk dapat digunakan dalam image enhancement bagi produk elektronik consumer.

Untuk mengatasi keterbatasan dari HE dan mempertahankan kecerahan citra, beberapa teknik $\mathrm{HE}$ dengan kemampuan mempertahankan 
kecerahan citra telah diperkenalkan diantaranya Kim (1997) memperkenalkan metode Brightness Preserving Bi-Histogram Equalization (BBHE), BBHE membagi histogram input citra kedalam 2 bagian berdasarkan rataan dari citra input dan setiap bagian di equalized secara independen. Hasilnya, rataan kecerahan dapat dipertahankan karena rataan kecerahan dari citra asli telah disimpan sebelumnya, Reference [4] dalam penelitiannya menghasilkan metode Dualistic Sub-Image Histogram Equalization (DSIHE), yang mirip dengan solusi BBHE dengan perbedaan dalam cara mempartisi histogram dimana DSIHE menggunakan median dari citra input dibanding rataan kecerahan pada BBHE. Chen and Ramli (2003) memperkenalkan metode Minimum Mean Brightness Error BiHistogram Equalization (MMBEBHE) yang dimaksudkan sebagai penyempurnaan dari metode BBHE yang mampu mempertahankan tingkat kecerahan secara maksimal. Algoritma ini menemukan error minimum pada rataan kecerahan antara citra asli dan citra yang telah diproses dan kemudian menentukan titik optimal sebagai titik pemisah alih-alih menggunakan rataan atau median dari citra masukan. Meskipun, metode ini dapat menghasilkan peningkatan kontras yang baik tetapi juga menyebabkan efek samping yang mengganggu bergantung terhadap variasi dari distribusi skala abu-abu pada histogram. Recursive Mean Separate HE (RMSHE) merupakan versi pengembangan lain dari BBHE [5]. Metode ini secara rekursif memisahkan histogram kedalam multi histogram (tidak hanya dua histogram seperti pada metode BBHE). Pada awalnya dua sub-histogram dibentuk berdasarkan tingkat rataan kecerahan dari histogram asli. Selanjutnya rataan kecerahan yang diperoleh dari dua sub-histogram sebelumnya digunakan sebagai titik pemisah kedua dan ketiga dalam membuat tambahan sub-histogram. Dengan cara yang sama, algoritma dieksekusi secara rekursif hingga jumlah sub-histogram yang diinginkan tercapai. Kemudiaan pendekatan HE diaplikasikan secara independen untuk setiap sub-histogram. Metode yang telah dibahas sebelumnya pada dasarnya menggunakan teknik dasar membagi histogram menjadi beberapa sub-histogram dengan menggunakan nilai mean atau median dari nilai kecerahan. Pada beberapa metode yang telah dibahas tingkat kecerahan dapat dipertahankan dengan baik meskipun tidak dapat memperluas lebih jauh area dari sub-histogram yang terletak dekat dengan nilai minimum atau maksimum dari range dinamis dan masih belum terbebas sepenuhnya dari efek samping yang mengganggu [6].

Untuk mengatasi permasalahan yang dinyatakan sebelumnya, Reference [7] memperkenalkan teknik Dynamic Histogram Equalization (DHE). DHE mempartisi histogram asli berdasarkan local minima meskipun dengan cara ini DHE tidak mempertahankan tingkat kecerahan. Kemudian untuk mengatasi hal ini, Ibrahim and Kong memperkenalkan Brightness Preserving Dynamic Histogram Equalization (BPDHE) [8]. Metode ini mempartisi histogram citra berdasarkan local maxima dari histogram. Metode ini kemudian memberikan dynamic range baru untuk setiap partisi. Terakhir, intensitas output di normalisasi untuk membuat intensitas rata-rata dari citra resultan sama dengan citra inputnya. Meskipun BPDHE menghasilkan performa yang baik dalam mempertahankan kecerahan citra, nilai rasio untuk normalisasi kecerahan mempunyai peran penting. Nilai rasio yang kecil dapat mengakibatkan peningkatan kontras yang tidak signifikan. Untuk nilai rasio yang besar ( Nilai rasio > 1), Nilai intensitas akhir dapat melebihi nilai intensitas maksimum dari dynamic range output. Piksel-piksel yang terkena nilai intensitas yang berlebih akan dikuantisasi ke nilai intensitas maksimum dari derajat keabuan dan menghasilkan masalah intensitas saturasi. Metode Brightness Preserving Dynamic Fuzzy Histogram Equalization (BPDFHE) diperkenalkan oleh kong (2008) yang merupakan versi peningkatan dari BPDHE yang menggunakan statistik fuzzy untuk merepresentasikan dan memproses citra digital. Memproses dan merepresentasikan citra dalam domain fuzzy memungkinkan untuk menangani ketidakpastian dari nilai derajat keabuan dengan lebih baik sehingga menghasilkan peningkatan performa. BPDFHE memanipulasi histogram citra sedemikian rupa hingga hanya redistribusi dari derajat keabuan yang berpengaruh sedangkan remapping histogram tidak memberikan pengaruh.

Untuk mengatasi keterbatasan tersebut, peneilitan ini akan menyajikan suatu model modifikasi histogram sederhana untuk peningkatan enhancement citra diam dengan tujuan meningkatkan kontras citra dengan tetap mempertahankan derajat kecerahan citra dan detail dari citra.

Histogram Equalization: histogram didefinisikan sebagai statistik distribusi probabilitas dari setiap derajat keabuan dalam citra digital. Histogram Equalization (HE) merupakan teknik umum bagi keperluan peningkatan kontras pada citra. Kontras citra dinyatakan oleh derajat dinamisnya (Dynamic Range) yang didefinisikan sebagai rasio antara intensitas piksel paling terang dan paling gelap. Histogram memberikan informasi kontras dan distribusi intensitas keseluruhan dari citra.

Misalkan $\mathrm{f}$ adalah citra input yang terdiri dari $\mathrm{L}$ diskrit derajat keabuan yang dinyatakan sebagai $\{f 0, f 1, \ldots, f \mathrm{~L}-1)$. Untuk suatu citra yang diberikan $\mathrm{f}$, fungsi probabilitas $\mathrm{P}(\mathrm{fk})$ dinyatakan sebagai

$$
P\left(f_{k}\right)=\frac{n^{k}}{n}
$$


Untuk $\mathrm{k}=0,1,2, \ldots, \mathrm{L}-1$, dimana $\mathrm{n}_{\mathrm{k}}$ menyatakan jumlah kemunculan derajat abu-abu $f_{k}$ muncul dalam citra input $f$ dan $n$ adalah total jumlah sampel dalam citra input. $\mathrm{P}\left(\mathrm{f}_{\mathrm{k}}\right)$ berhubungan dengan histogram citra input yang merepresentasikan jumlah piksel yang memiliki intensitas spesifik $f_{k}$. Realisasinya hubungan $f_{k}$ vs $n_{k}$ disebut histogram dari citra input $\mathrm{f}$. Maka fungsi kepadatan kumulatif dinyatakan sebagai

$$
C\left(f_{k}\right)=\sum_{j=0}^{L-1} p\left(f_{j}\right)
$$

Untuk $\mathrm{K}=0,1,2, \ldots, \mathrm{L}-1$. Maka menurut definisi $\mathrm{C}\left(\mathrm{f}_{\mathrm{L}-1}\right)=1$. Histogram Equalization merupakan metode yang memetakan citra input ke dalam seluruh dynamic range. $\left(f_{0} f_{L-1}\right)$, dengan menggunakan fungsi distribusi kumulatif sebagai fungsi transformasi. Maka didefinisikan fungsi transformasi $\mathrm{T}(\mathrm{f})$ berdasarkan fungsi densitas kumulatif sebagai berikut:

$$
T(f)=\left\{f_{0}+\left(f_{L-1}-f_{0}\right) C\left(f_{k}\right)\right\}
$$

Kemudian, citra yang telah dienhanced dari HE g $=\mathrm{g}(\mathrm{i}, \mathrm{j})$ dapat dinyatakan sebagai berikut:

$$
g(i, j)=T(f)=\{T(f(i, j)) \mid \forall f(i, j) \in f\}
$$

\section{Dimana:}

$\mathrm{f}$ dan $\mathrm{g}=$ citra asli dan citra yang dienhanced.

$(\mathrm{i}, \mathrm{j})=$ Koordinat $2 \mathrm{D}$ dari citra.

$\mathrm{T}$ =fungsi transformasi intensitas untuk mapping citra asli ke seluruh dynamic range $\left(\mathrm{f}_{0}, \mathrm{f}_{\mathrm{L}-1}\right)$.

Permasalahannya, HE menghasilkan effect noise checkboard pada image yang dienhanced. Masalah lainnya adalah metode ini ikut meningkatkan noise dari citra input.

\section{Metodologi Penelitian}

Dalam penelitian ini, sebuah kerangka modifikasi histogram sederhana akan dirancang untuk mempertahankan kecerahan rata-rata pada citra yang mengarah ke peningkatan kontras. Blok diagram dari metode yang dirancang dapat dilihat pada gambar 1 dan berikut urutan langkah dari metode yang dirancang

Langkah 1 : Komputasi dan modifikasi histogram : histogram dari citra asli dimodifikasi agar mampu mempertahankan derajat kecerahan yang berkaitan dengan informasi utama dari citra dan melemahkan detail yang tidak dibutuhkan

Langkah 2: Partisi dan Ekualisasi Histogram : histogram yang telah dimodifikasi dibagi kedalam dua sub-histogram berdasarkan rataan input dari citra asli. Salah satu dari sub-histogram yang telah dimodifikasi merupakan kumpulan sampel yang sama atau kurang dari rataan sedangkan yang sub- histogram yang satunya merupakan kumpulan sampel yang lebih besar dari nilai rata-rata. Kemudian ekualisasi histogram dilakukan pada setiap partisi dari histogram yang telah dimodifikasi secara independen kemudian hasilnya akan dikombinasikan bersama untuk membentuk citra yang telah dienhanced secara lengkap.

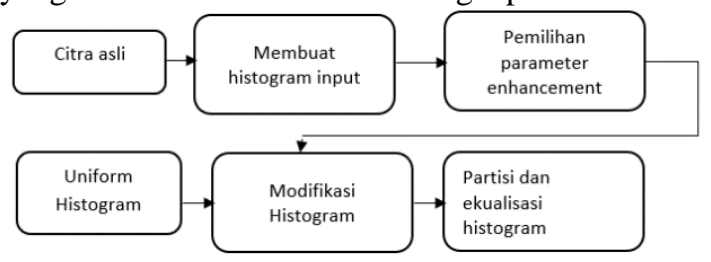

Gambar 1. Blok Diagram Metode yang Diusulkan

$$
\bar{H}=\frac{h_{i}+\gamma u}{l+\gamma}=\left(\frac{l}{l+\gamma}\right) h_{i}+\left(\frac{\gamma}{l+\gamma}\right) u
$$

Dimana:

$\overline{\mathrm{H}}=$ histogram termodifikasi

$\mathrm{U}=$ Uniform histogram

$\gamma=$ Parameter enhancement

Berbagai tingkat peningkatan kontras dapat dicapai dengan mengubah nilai parameter y. HE yang diperoleh dengan $\mathrm{y}=0$ merupakan $\mathrm{HE}$ standar dan semakin nilai y mendekati tak terhingga akan mempertahankan kontras citra asli.

Partisi dan Ekualisasi Histogram: Misalkan citra input $\mathrm{x}$. Berdasarkan rata-rata input Xm, Histogram termodifikasi H dipisahkan menjadi 2 sub histogram $\mathrm{H}_{\mathrm{L}}$ dan $\mathrm{H}_{\mathrm{u}}$

$$
\begin{aligned}
& H=H_{L} \cup H_{U} \\
& \text { Dimana: } \\
& H_{L}=\left\{X(i, j) \mid X(i, j) \leq X_{m}, \forall X(i, j) \in H\right\} \\
& \text { Dan } \\
& H_{U}=\left\{X(i, j) \mid X(i, j) \leq X_{m}, \forall X(i, j) \in H\right\}
\end{aligned}
$$

Kemudian tentukan fungsi probabilitas densitas yang sesuai untuk sub histogram termodifikasi $\overline{\mathrm{H}}_{\mathrm{L}}$ dan $\overline{\mathrm{H}}_{\mathrm{u}}$ sebagai berikut:

$$
P_{L}\left(X_{k}\right)=\frac{n_{L}^{k}}{n_{L}}
$$

Dimana $\mathrm{k}=0,1, \ldots, \mathrm{m}$ dan

$$
P_{U}\left(X_{k}\right)=\frac{n_{U}^{k}}{n_{U}}
$$

Dimana:

$\mathrm{K}=\mathrm{m}+1, \mathrm{~m}+2, \ldots, \mathrm{L}-1$

$\mathrm{N}_{\mathrm{u}}^{\mathrm{k}}, \mathrm{N}_{\mathrm{L}}^{\mathrm{k}}=$ jumlah yang sesuai untuk $\mathrm{X}_{\mathrm{k}}$ dalam $\overline{\mathrm{H}}_{\mathrm{L}}$ dan $\overline{\mathrm{H}}_{\mathrm{u}}$

$\mathrm{N}_{\mathrm{L}}^{\mathrm{k}}, \mathrm{N}_{\mathrm{u}}^{\mathrm{k}}=$ jumlah banyaknya sampel dalam $\overline{\mathrm{H}}_{\mathrm{L}}$ dan $\overline{\mathrm{H}}_{\mathrm{u}}$

Dapat dilihat bahwa $\mathrm{P}_{\mathrm{L}}\left(\mathrm{X}_{\mathrm{k}}\right)$ dan $\mathrm{P}\left(\mathrm{X}_{\mathrm{k}}\right)$ teasosiasi dengan histogram termodifikasi dari citra masukan yang merepresentasikan jumlah piksel yang mempunyai intensitas spesifik $X_{\mathrm{k}}$. Kemudian fungsi kumulatif densitas untuk sub-histogram termodifikasi $\overline{\mathrm{H}}_{\mathrm{L}}$ dan $\overline{\mathrm{H}}_{\mathrm{u}}$ dinyatakan sebagai berikut

$$
\begin{aligned}
& C_{L}\left(X_{k}\right)=\sum_{j=0}^{k} P_{L}\left(X_{j}\right) \\
& \text { Dan }
\end{aligned}
$$




$$
C_{u}\left(X_{k}\right)=\sum_{j=m+1}^{k} P_{u}\left(X_{j}\right)
$$

Selanjutnya berdasarkan fungsi kumulatif densitas dinyatakan fungsi transformasi berikut:

$$
\begin{aligned}
& f_{L}\left(X_{k}\right)=X_{0}+\left(X_{m}-X_{0}\right) C_{L}\left(X_{k}\right) \\
& \operatorname{Dan} \\
& f_{u}\left(X_{k}\right)=X_{m+1}+\left(X_{L+1}-X_{0}\right) C_{L}\left(X_{k}\right)
\end{aligned}
$$

Berdasarkan dari fungsi transformasi tersebut, sub citra yang rusak di equalisasi secara independen dan komposisi dari hasil ekualisasi sub citra merupakan citra yang dienhanced

\section{Hasil dan Pembahasan}

Dalam penelitian ini dilakukan perbandingan antara metode yang dihasilkan dengan metode konvensional dalam peningkatan citra sepert HE, BBHE, dan DHE. Penilian subjektif untuk membandingkan kualitas visual turut digunakan. gambar 2a menunjukkan citra asli yang belum dienhanced. Gambar 2b menunjukkan citra yang dienhanced menggunakan $\mathrm{HE}$, terlihat bahwa $\mathrm{HE}$ meningkatkan kontras secara signifikan pada gambar akan tetapi terlihat juga turut memperkuat noise pada citra berupa artifak dan efek samping yang tidak diinginkan. Gambar 2c memperlihatkan citra yang diproses menggunakan metode BBHE, terlihat bahwa citra menjadi tampak tidak natural dan tidak ada peningkatan yang signifikan terhadap citra. Gambar $2 \mathrm{f}$ menunjukkan citra yang lebih baik, tidak terlihat adanya artifak, dan kecerahan gambar dapat dipertahankan dengan baik sehingga menghasilkan enhancemenet yang lebih alami.



Gambar 2: Hasil simulasi untuk citra "girl" ; 2a) Citra asli, 2b) citra dengan metode $\mathrm{HE}, 2 \mathrm{c}$ ) citra dengan metode BBHE, 2f) citra dengan metode yang diusulkan.

Melalui pengamatan secara visual pada citra, dapat terlihat jelas hanya metode yang diusulkan yang mampu menghasilkan citra yang terlihat alami tapi tetap mampu memberikan peningkatan kontras. Lebih jauh kualitas dari citra uji yang dienhanced menggunakan beberapa metode yang telah disebutkan diukur menggunakan CII, AIC seperti pada tabel 1. Dari hasil analisis nilai CII yang disajikan pada tabel 1 , tampak metode yang diusulkan mempunyai nilai CII yang lebih besar dibandingkan metode konvesioanal, karena itu metode yang diusulkan menigktakan kontras lokal dari citra lebih baik dari metode konvesional lainnya. Sesuai dengan tabel 2, metode yang diusulkan menghasilkan nilai AIC tertinggi, sehingga menjadikannya metode yang terbaik dalam mempertahankan detail gambar. Selain itu hasil AIC menunjukkan metode yang diusulkan dapat meningkatkan kontras dari citra masukan dengan lebih baik yang diindikasikan dengan nilai AIC yang lebih besar dari metode konvensional lainnya.

TABel 1. PERBANDINGAN NILAI CII

\begin{tabular}{|l|c|c|c|l|}
\hline Berkas citra & HE & BBHE & DHE & $\begin{array}{c}\text { Metode } \\
\text { yang } \\
\text { diusulkan }\end{array}$ \\
\hline Gadis & 1.3124 & 1.3337 & 1.2192 & 1.3335 \\
\hline Lena & 1.4202 & 1.4412 & 1.3612 & 1.4374 \\
\hline Kameramen & 1.1783 & 1.1761 & 1.0325 & 1.1115 \\
\hline
\end{tabular}

TABEl 2. PERBANDINGAN NILAI AIC

\begin{tabular}{|l|l|l|l|l|}
\hline $\begin{array}{c}\text { Berkas } \\
\text { citra }\end{array}$ & HE & BBHE & DHE & $\begin{array}{c}\text { Metode } \\
\text { yang } \\
\text { diusulkan }\end{array}$ \\
\hline Gadis & 5.3792 & 5.3893 & 5.5422 & 5.3823 \\
\hline Lena & 7.3456 & 7.3551 & 7.2242 & 7.3656 \\
\hline Kameramen & 6.7663 & 6.8088 & 6.7464 & 6.8799 \\
\hline
\end{tabular}

\section{Kesimpulan}

Dalam penelitian ini, kerangka modifikasi histogram dihasilkan untuk peningkatan kontras citra. Histogram dari citra asli di modifikasi terhadap uniform histogram dan memisahkan histogram yang dimodifikasi menjadi dua sub-histogram berdasarkan mean dari citra asli dan kemudian melakukan ekualisasi secara independen untuk mempertahankan kecerahan citra. Tingkat dari peningkatan citra dapat diatur tergantung dari citra masukan dengan memberi variasi nilai pada tiap parameter enhancement. Hasil eksperimen yang dilakukan menunjukkan metode yang diusulkan dapat secara signifikan mengeliminir efek tampilan yang pudar pada citra. Selain itu metode ini dapat meningkatkan kualitas citra tanpa menyebabkan hilangnya detail citra dan juga tidak menghasilkan artefak-artefak yang tidak diinginkan pada citra.

\section{Referensi}

[1] Kabir, M.H., M.A.A Wadud and O. Chae, "Brightness Preserving Image Contrast Enhancement Using Weighted Mixture of Global and Local Transformation Function" Int. Arab J. Inf. Technol., 7:403-410

[2] Chyan, P. and S.C. Sumarta., "Rancang Bangun Mesin Pencari Citra Dengan Pendekatan Temu Balik Berbasis Konten", Jurnal ilmiah Tematika, Vol. 3, No. 2, pp. 31-39. 2015.

[3] Chyan, P. and S.C. Sumarta., " Sistem Temu Balik Citra Menggunakan Ekstraksi Fitur Citra Dengan Klasifikasi Region Untuk Identifikasi Objek ", Jurnal ilmiah Tematika, Vol. 2, No. 2, pp. 21-29, 2014.

[4] Wang, C. and Z. Ye, "Brightness Prrserving Histogram Equalization With Maximum Entropy : A Variational Perspective. IEEE Trans. Consumer Electron., 51: 13261334. 2005

[5] Chen, S.D. and A.R Ramli, "Minimum Mean Brightness Error bi-histogram Equalization In Contrast Enhancement. IEEE Trans, Consum Electron., 49: 1310-1319. 2003 
[6] Chen, Z.Y., B.R Abidi, D.L. Page and M.A Abidi, "Gray Level Grouping (GLG) : an Automatic Method for Optimized Image Contrast Enhancement Part I : The Basic Method. IEEE Trans. Image Process , 15: 2290-2302. 2006

[7] Abdullah-Al-Wadud, M., M.H Kabir, M.A.A Dewan and O. Chae, " A Dynamic Histogram Equalization for Image Contrast Enhancement . IEEE Trans. Comsumer Electron., 53:593-600. 2007

[8] Kong, N.S.P., and H. Ibrahim, “Color Image Enhancement Using Brightness Preserving Dynamic Histogram Equalization. IEEE Trans. Consumer Electron., 54:19621968. 2008 